\title{
Separation of enantiomers of a chiral epoxide by simulated moving bed chromatography
}

\author{
Luís S. Pais, José M. Loureiro, Alírio E. Rodrigues* \\ Laboratory of Separation and Reaction Engineering, School of Engineering, University of Porto, Rua dos Bragas, 4099 Porto Codex, \\ Portugal
}

\begin{abstract}
The paper deals with chiral separation by simulated moving bed (SMB) chromatography. The separation of chiral epoxide enantiomers in microcrystalline cellulose triacetate using methanol as eluent is considered as illustrative example. The use of microcrystalline cellulose triacetate for the chromatographic separation of enantiomers is first reviewed and a methodology for obtaining basic data (adsorption equilibrium isotherms, axial dispersion and mass transfer coefficient) is discussed. A model for the prediction of the cyclic steady-state performance of the SMB, based on the analogy with the true moving bed, is developed assuming multicomponent adsorption equilibria, axial dispersion flow and linear driving force approximation to describe the intraparticle mass transfer rate. The simulation package is used to predict the effect of operating variables on the process performance and to define the regions for enantiomer separation. A simple optimization procedure is proposed for choosing the best SMB operating conditions. This procedure is extensively tested for the separation of chiral epoxide enantiomers. The experimental operation of a SMB pilot unit was carried out for this system. Purities and recoveries higher than $90 \%$ were obtained for both extract and raffinate, using a $420 \mathrm{ml}$ inventory of stationary phase. The SMB pilot allows the continuous resolution of $52 \mathrm{~g}$ of racemic mixture per day and per liter of bed, with a solvent consumption of 0.41 of mobile phase per gram of racemic mixture processed. The simulation package is also used to predict the steady-state internal concentration profiles for the SMB operation with reasonable agreement with experimental results. (C) 1998 Elsevier Science B.V. All rights reserved.
\end{abstract}

Keywords: Simulated moving bed chromatography; Enantiomer separation; Preparative chromatography; Computer simulation; Optimization; Epoxides

\section{Introduction}

In 1973, Hesse and Hagel [1] proposed for the first time the use of microcrystalline cellulose triacetate for the chromatographic separation of enantiomers. They reported the complete separation of $100 \mathrm{mg}$ Tröger's base using $40 \mathrm{~g}$ microcrystalline cellulose triacetate and ethanol as eluent. The key to success was the heterogeneous acetylation of microcrystal-

\footnotetext{
*Corresponding author. Tel.: +351 2 2041671, Fax: +3512 2041674, E-mail: arodrig@fe.up.pt
}

line cellulose and subsequent swelling in boiling alcohol, so that the original structure of the polymer was preserved. This microcrystalline cellulose triacetate in its swollen state proves to be able to the chromatographic resolution of various chiral compounds [2-5].

Although the ability of microcrystalline cellulose triacetate to chiral resolution has been reported by several authors, the mechanism of the chiral recognition is still unclear. Hesse and Hagel [6] proposed the concept of inclusion chromatography: the interaction with the chiral compounds occurs by inclusion 
into the asymmetric cavities of the polysaccharide network. The strength of the interaction will be determined by the fit of the chiral species to the chiral cavities of the swollen microcrystalline cellulose triacetate. On the contrary, of common stationary phases, adsorption on microcrystalline cellulose triacetate seems to be more influenced by steric effects than it is by the chemical nature of the interaction between the chiral species and the stationary phase substituents. Hesse and Hagel highlighted the crucial contribution of the crystalline structure of the adsorbent. As it was mentioned by several authors, only the cellulose triacetate obtained from the heterogeneous acetylation of microcrystalline cellulose has chiral recognition properties. These properties are mostly lost if the cellulose triacetate is obtained by homogeneous acetylation because the dissolution will cause the loss of crystallinity of the adsorbent structure. The microcrystalline structure of this adsorbent will determine the geometric arrangement of the chiral environment [1,6-9].

The chiral recognition property is not necessarily confined to microcrystalline cellulose triacetate. Shibata et al. [4] and Okamoto [10] proposed the use of cellulose triacetate and other cellulose derivatives prepared under homogeneous conditions. This material is dissolved, reprecipitated and coated onto the surface of a silica support. The homogeneous acetylation causes the loss of the microcrystalline structure of the cellulose triacetate, leading to a material with a lower chiral recognition ability. Its chromatographic performance can, however, be enhanced, for example, by controlling the particle size. It should be pointed out that the chiral discrimination mechanism of coated cellulose triacetate is quite different from the one described for the microcrystalline form. Various applications of this alternative material can be found in the literature $[4,11,12]$.

In the last years several stationary phases have been developed for the preparative chromatographic separation of enantiomers. Since microcrystalline cellulose triacetate is a natural product and can be synthesized at low cost, it is a material of choice for preparative chromatographic applications [13]. Some semi-preparative and preparative chiral separations on cellulose triacetate have been reported in literature [3,5,14-18].

The simulated moving bed (SMB) process was patented in the early 1960 s by UOP for separating petrochemical mixtures [19-23]. Developed for hydrocarbon separations, the SMB technology has been recently applied as a new method for the preparation of single enantiomer drugs [24-28]. The need for optically pure compounds is increasing as regulatory aspects become more stringent. The separation of enantiomers is an important issue in various areas, particularly in the health-related field. It is well known that isomers can have different and opposing pharmacological effects, so new chiral separation methods are being proposed nowadays to produce single enantiomeric forms of chiral drugs [29-33].

The SMB process basic principle is a flow scheme that takes advantages of continuous and countercurrent movement of liquid and solid without actual movement of the adsorbent. This counter-current movement is simulated by an appropriated flow switching sequence: the adsorbent bed is divided into a number of fixed-bed columns, while the inlet and outlet lines move simultaneously one column at fixed time intervals in the direction of the liquid phase flow. Hence, the SMB process shares the same advantages of the real counter-current scheme, bypassing the obvious problems concerning the solid movement. If solid (switch time interval) and liquid flow-rates are conveniently chosen, it is possible to recover continuously purified products, eliminating the drawback of dilution of species and low adsorbent utilization present in batch chromatography [34-37].

Chiral stationary phases used in preparative chromatography are being applied for enantiomer separations by SMB chromatography. A procedure to optimize the SMB separation conditions by choosing the best chiral stationary phase/eluent combination have been recently proposed by Schulte et al. [38]. Following the increasing interest in the SMB technology for chiral separations, recent examples of resolution of enantiomers by SMB chromatography from laboratory to industrial scale have been reported and summarized elsewhere [17,37,39].

SMB chiral chromatography is, in this way, a promising technique for the preparative production of single enantiomeric drugs able to compete to up to now dominating techniques such as elution batch chromatography, diastereoisomeric crystallization, or asymmetric synthesis. SMB chromatography is es- 
sentially a binary mixture separation technique, hence particularly suitable for racemic resolutions. Among the main advantages of the SMB chromatography is the fact that is a continuous process able to perform high purity and recovery for low selectivity separations with reductions in eluent consumption and adsorbent requirements.

The main problem of the SMB operation is the choice of correct solid (switch time interval) and liquid flow-rates. Designed for high productivity separations, SMB units usually operate at high feed concentrations leading to non-linear competitive adsorption behaviours. Therefore, modeling and simulation tools are of crucial importance before running the system. This requires a knowledge of some basic information on equilibrium and kinetic parameters.

This work leads with the resolution of a racemic mixture of a chiral epoxide (1a,2,7,7a-tetrahydro-3methoxynaphth-[2,3b]oxirene, Sandoz Pharma, Basel, Switzerland) using a SMB pilot unit, the Licosep 12-26, developed by Separex and the French Institute of Petroleum. The Licosep technology is now available through Novasep (Vandrœuvre-lèsNancy, France). The chiral separation was carried out with a $420 \mathrm{ml}$ inventory of microcrystalline cellulose triacetate with a particle diameter greater than $45 \mu \mathrm{m}$. The eluent used was pure methanol. The objective of this paper is to present a complete procedure to characterize and perform a SMB chromatographic separation of enantiomers. This procedure is illustrated with the chiral epoxide system mentioned above and involves the following steps:

1. Preparation of the chiral stationary phase and column packing procedure

2. Hydrodynamic study of a SMB column

3. Experimental measurement of competitive adsorption isotherms of chiral mixtures

4. Development of a package to predict the steadystate performance of a SMB chromatographic system

5. Understanding SMB process by using the simulation package to study the effect of model parameters and operation conditions on the SMB performance

6. Optimization of the SMB operating conditions

7. Experimental operation of the Licosep SMB pilot unit for the separation of enantiomers and com- parison between experimental and theoretical predictions

\section{Experimental}

\subsection{High-performance liquid chromatography (HPLC) apparatus}

The samples collected for the experimental determination of adsorption isotherms and in the SMB operation were analyzed in a HPLC system using a $250 \mathrm{~mm} \times 10 \mathrm{~mm}$ column, filled with microcrystalline cellulose triacetate, particle diameter $10 \mu \mathrm{m}$ (Merck, Darmstadt, Germany). Pure methanol was used as eluent and the outlet concentration was determined by UV detection at $220 \mathrm{~nm}$. The HPLC system (Gilson, Villiers le Bel, France) includes one piston pump (Model 305) with a 10.SC piston pump head, a Model 115 UV detector, a Model 805 manometric module and an IBM 386 personal computer; the system is completely automated.

\subsection{SMB pilot unit}

The SMB pilot unit used in this work is the Licosep 12-26 (Novasep). It is a continuous chromatographic system constituted by 12 columns connected in series. The columns are Superformance 300-26 (Merck) with $26 \mathrm{~mm}$ internal diameter and adjustable length $(5-20 \mathrm{~cm})$. They have a jacket which allows operation of the SMB up to $60^{\circ} \mathrm{C}$. Each column is connected with four lines (eluent, feed, extract and raffinate lines) and 48 two-way highpressure pneumatic valves (TOP Industrie, France) allow the connection of the inlet-outlet lines of the columns. A three-head membrane pump (Milroyal, Pont St. Pierre, France) is used for the recycle flow. The other flows (eluent, feed, extract and raffinate) are controlled by four pumps Merck-Hitachi (Darmstadt, Germany), connected to the computer via RS 232. The system temperature is measured and controlled through a thermostatic bath. The SMB unit can stand pressures up to 60 bar. The SMB pilot is controlled by a central system using the Licosep control software. 
Table 1

Test of SMB columns with the non-retained compound $(50 \mu \mathrm{g})$

\begin{tabular}{lcccr}
\hline Column & Length $(\mathrm{cm})$ & Deviation $(\%)$ & Retention time $(\mathrm{min})$ & Deviation $(\%)$ \\
\hline 1 & 10.1 & 1.76 & 4.43 & 1.98 \\
2 & 9.8 & -1.26 & 4.27 & -1.70 \\
3 & 10.0 & 0.76 & 4.37 & 0.60 \\
4 & 9.9 & -0.25 & 4.33 & -0.32 \\
5 & 9.9 & -0.25 & 4.30 & -1.01 \\
6 & 9.9 & -0.25 & 4.38 & 0.83 \\
7 & 9.9 & -0.25 & 4.36 & 0.37 \\
8 & 9.9 & -0.25 & 4.31 & -0.78 \\
Average & 9.925 & & 4.34 & \\
\hline
\end{tabular}

Flow-rate: $8 \mathrm{ml} / \mathrm{min}$.

\subsection{Stationary phase and SMB column packing procedure}

The microcrystalline cellulose triacetate used as stationary phase (Merck) was swollen in boiling methanol, followed by a decantation procedure. The final material has a particle diameter greater than 45 $\mu \mathrm{m}$. A packing procedure proposed by Nicoud [40] was used to fill eight SMB columns. Each column was packed with the adsorbent material and the bed was compacted with methanol at a progressive flowrate of $90 \mathrm{ml} / \mathrm{min}$ during $1 \mathrm{~h}$. After this step, the pressure at the column outlet was increased to $30 \mathrm{bar}$ and a constant flow-rate of $50 \mathrm{ml} / \mathrm{min}$ was imposed during $20 \mathrm{~min}$. The adsorbent bed was compacted until the column reached approximately $10 \mathrm{~cm}$ length.

The eight columns were tested individually with a non-retained compound (1,3,5-tri-tert.-butylbenzene, Sigma, St. Louis, MO, USA) [2], to compare retention times. Table 1 shows test results with the non-retained compound. Retention times are very reproducible, showing deviations smaller than $2 \%$.

\subsection{Hydrodynamic study of a SMB column}

One SMB column prepared following the procedure described above was used to carry out a hydrodynamic study. The total porosity, $\varepsilon_{\mathrm{T}}$, was evaluated by injecting a non-retained compound (1,3,5-tri-tert.-butylbenzene). A value of $\varepsilon_{\mathrm{T}}$ was found, in agreement with other published results for microcrystalline cellulose triacetate (see Table 2).

The influence of the linear velocity, $v$, upon plate height, $H$, was also examined by using the nonretained compound. The usual decrease of $H$ upon decreasing $v$ can be seen in Fig. 1. Unfortunately, pure enantiomers of the chiral epoxide were not available. Anyway, 90\% pure enantiomers were injected and 1370 and $1550 \mu \mathrm{m}$ plate heights were found for a flow-rate of $22.8 \mathrm{ml} / \mathrm{min}(1.8 \mathrm{~mm} / \mathrm{s})$ at $25^{\circ} \mathrm{C}$. Although these results could be affected by the

Table 2

Total porosity of columns filled with microcrystalline cellulose triacetate

\begin{tabular}{|c|c|c|c|c|}
\hline $\begin{array}{l}\text { Column } \\
\text { dimensions } \\
L \times D(\mathrm{~mm})\end{array}$ & $\begin{array}{l}\text { Particle } \\
\text { diameter } \\
d_{\mathrm{P}}(\mu \mathrm{m})\end{array}$ & Eluent & $\begin{array}{l}\text { Total } \\
\text { porosity } \\
\varepsilon_{\mathrm{T}}\end{array}$ & Ref. \\
\hline $250 \times 8$ & $10-20$ & Ethanol-4\% water & 0.60 & [2] \\
\hline $243 \times 40$ & $20-30$ & Ethanol-4\% water & 0.625 & {$[14]$} \\
\hline $250 \times 10$ & 10 & Methanol & 0.73 & {$[41]$} \\
\hline $250 \times 5$ & $15-25$ & Ethanol-5\% water & 0.63 & [8] \\
\hline $445 \times 12.5$ & $25-40$ & Methanol & 0.70 & {$[42]$} \\
\hline $99 \times 26$ & 45 & Methanol & 0.67 & This work \\
\hline
\end{tabular}




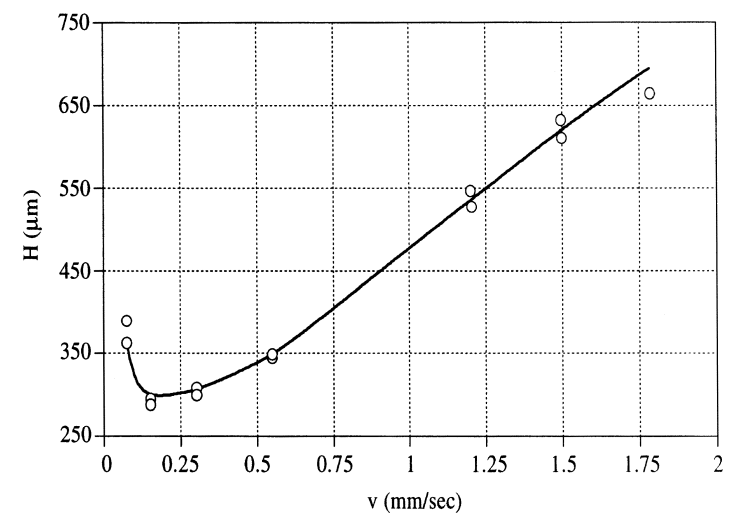

Fig. 1. Influence of the linear velocity upon plate height for the non-retained compound (1,3,5-tri-tert.-butylbenzene).

presence of a small amount of the other enantiomer, they are qualitatively in agreement with previous work published by Koller et al. [2] for the separation of various enantiomers in microcrystalline cellulose triacetate.

A breakthrough curve with the non-retained compound was carried out to estimate the axial dispersion in the SMB column. A Peclet number of $\mathrm{Pe}=$ 1000 was found by comparing experimental and simulated results from a model which includes axial dispersion in the interparticle fluid phase, accumulation in both interparticle and intraparticle fluid phases and assuming that the average pore concentration is equal to the bulk fluid concentration; this assumption is justified by the fact that the ratio of time constant for pore diffusion and space time in the column is of the order of $10^{-4}$ (see Fig. 2).

\subsection{Experimental determination of competitive adsorption isotherms}

To develop chromatographic separation processes such as SMB technology, modeling and simulation are essential issues of the design. The modeling of the chromatographic process requires the knowledge of the adsorption isotherms. When dealing with preparative scale separations it is advisable to determine experimentally the competitive adsorption isotherms, instead of predicting those from single component isotherms. Some examples of determination of competitive adsorption isotherms of en-

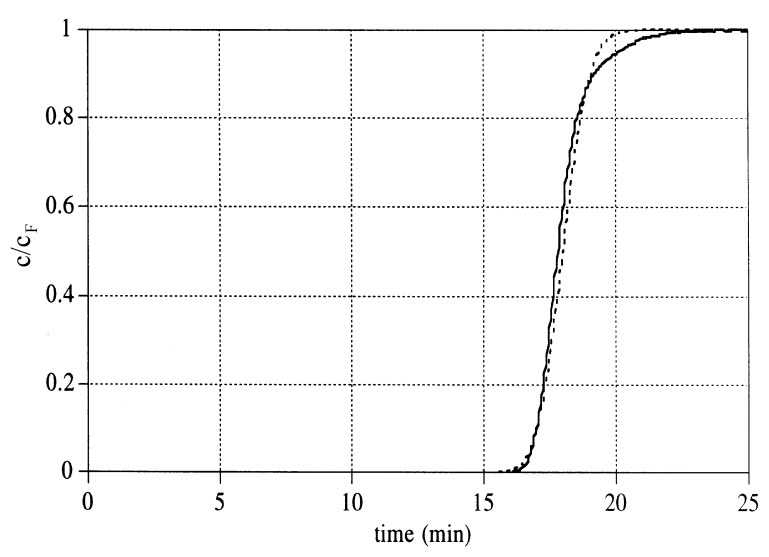

Fig. 2. Breakthrough curve obtained for the non-retained compound. Comparison between experimental (-) and model $(\cdot \cdots)$ results. Flow-rate: $2 \mathrm{ml} / \mathrm{min}$.

antiomers on chiral stationary phases were recently published [43-46].

Competitive adsorption isotherms were experimentally determined for the separation of chiral epoxide enantiomers (1a,2,7,7a-tetrahydro-3-methoxynaphth-[2,3b]oxirene), an intermediate from Sandoz Pharma (Fig. 3). The separation was carried out using microcrystalline cellulose triacetate as stationary phase and methanol as eluent at $25^{\circ} \mathrm{C}$. The method followed was a combination of static adsorption-desorption measurements checked with a dynamic method of frontal chromatography. In the adsorption-desorption method, a SMB column initially equilibrated with the eluent, is fed with a large amount of a solution with known concentrations $C_{\mathrm{A}}^{\mathrm{F}}$ and $C_{\mathrm{B}}^{\mathrm{F}}$, until equilibrium is reached. The column is then completely desorbed with the eluent. The eluted

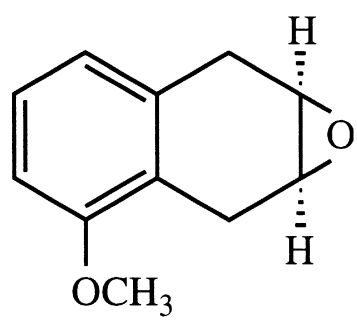

Fig. 3. Chiral epoxide (1a,2,7,7a-tetrahydro-3-methoxynaphth[2,3b]-oxirene). 
volume resulting from the desorption step is analyzed. The mass balance

$V^{\mathrm{d}} c_{i}^{\mathrm{d}}=\varepsilon V_{\mathrm{c}} c_{i}^{\mathrm{F}}+(1-\varepsilon) V_{\mathrm{c}} q_{i}^{*}$

will allow the knowledge of the concentration of each component retained in the particle, $q_{i}^{*}$, in equilibrium with the feed concentration, $c_{i}^{\mathrm{F}}$. In fact $q_{i}^{*}$ includes both the adsorbed phase concentration and the concentration in the fluid inside pores. This overall retained concentration $q_{i}^{*}$ is used to be consistent with the model used later in SMB simulations based on "homogeneous" particles. In this balance, $c_{i}^{\mathrm{d}}$ is the concentration of each component in the eluted volume obtained in the desorption step, $V^{\mathrm{d}}$ is the eluted volume, $V_{\mathrm{c}}$ is the column volume, and $\varepsilon$ the bed porosity. The bed porosity was taken as $\varepsilon=0.4$ since the total porosity was measured as $\varepsilon_{\mathrm{T}}=0.67$ and the particle porosity of microcrystalline cellulose triacetate is $\varepsilon_{\mathrm{p}}=0.45$ [42].

This procedure provides one point of the adsorption isotherm for each component $\left(c_{i}^{\mathrm{F}}, q_{i}^{*}\right)$. The determination of the complete isotherm will require a set of experiments using different feed concentrations. To support the isotherms measured by the adsorption-desorption procedure, a dynamic method of frontal chromatography is implemented. This method is based on the mathematical analysis of the response curves to a step change in feed concentration (adsorption) followed by the desorption of the column with pure eluent. A complete description of these and other methods of adsorption isotherms measurements with applications to preparative chromatography can be found in Seidel-Morgenstern and Nicoud [47]. It should be pointed out that, when using the dynamic method to describe the chromatographic curves in a SMB column, the shape of the front is not only influenced by thermodynamics but also by dispersion and mass transfer resistance phenomena. Hence, the value for the mass transfer coefficient will be predicted simultaneously with the adsorption data.

\subsection{Modeling competitive adsorption isotherms}

The binary Langmuir isotherm for mixtures of species $i$ and $j$ (Eq. (2)) is one of the most popular models used to represent adsorption isotherms.
$q_{i}^{*}=\frac{Q b_{i} C_{i}}{1+b_{i} C_{i}+b_{j} C_{j}}$

However, for many systems, this isotherm fails when the objective is to model chromatographic results. For instance, the multicomponent Langmuir isotherm takes into account the competition between species for the available chiral sites but does not predict the concentration dependency of the selectivity factor. It is well known that often the selectivity factor decreases with the increase of the concentration of chiral species. To overcome this lack of information, two different models have been widely used: the linear+Langmuir (Eq. (3)) and the biLangmuir (Eq. (4)) competitive isotherms.

$q_{i}^{*}=m C_{i}+\frac{Q b_{i} C_{i}}{1+b_{i} C_{i}+b_{j} C_{j}}$

$q_{i}^{*}=\frac{Q b_{i} C_{i}}{1+b_{i} C_{i}+b_{j} C_{j}}+\frac{\Theta \beta_{i} C_{i}}{1+\beta_{i} C_{i}+\beta_{j} C_{j}}$

As it was mentioned before, the mechanism of chiral recognition in microcrystalline cellulose triacetate involves the intercalation of the chiral solutes between the polymer chains. However, this mechanism does not exclude the occurrence of simple interaction in the surface of the adsorbent. Hence, chiral stationary phases provide two types of adsorption sites: one responsible for non-selective achiral interactions, the other for chiral selective interactions between the enantiomers and the stationary phase $[42,43,48]$.

Racemic (50\%) and 90\% pure solutions were used for adsorption isotherm measurements within a range of $0.25-5 \mathrm{~g} / 1$ concentrations. A pulse of a racemic mixture (5 g/l each enantiomer) was carried out to check the adsorption model and to predict the mass transfer coefficient. The other model parameters used in simulation were $\varepsilon=0.4$ and $\mathrm{Pe}=1000$.

The model used to fit experimental data for the chiral epoxide system was the linear + Langmuir adsorption isotherm (Eq. (3)) with the following results: $m=1.35, Q=7.32 \mathrm{~g} / 1, b_{\mathrm{A}}=0.087 \mathrm{l} / \mathrm{g}$ and $b_{\mathrm{B}}=0.163 \mathrm{l} / \mathrm{g}$; mass transfer coefficient, $k=0.4 \mathrm{~s}^{-1}$. Model and experimental results are compared in Figs. 4 and 5. Fig. 6 shows the influence of the enantiomers concentration on the selectivity factor. 

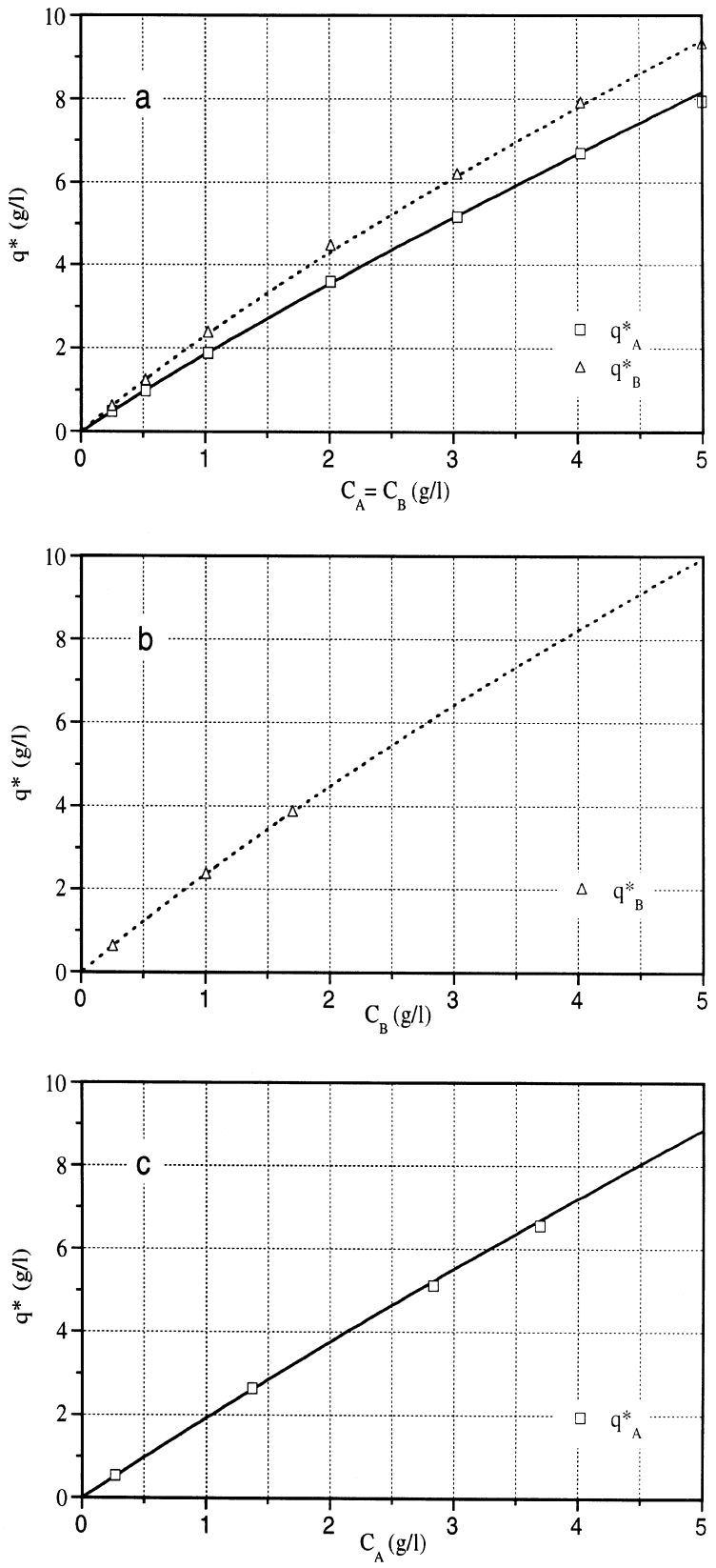

Fig. 4. Competitive adsorption isotherms. Comparison between experimental (points) and model (lines) results: (a) racemic mixtures; (b) feed with $90 \%$ purity in the more retained component (B); (c) feed with $92 \%$ purity in the less retained component (A). Squares and solid lines for the less retained component (A), triangles and dashed lines for the more retained component (B).

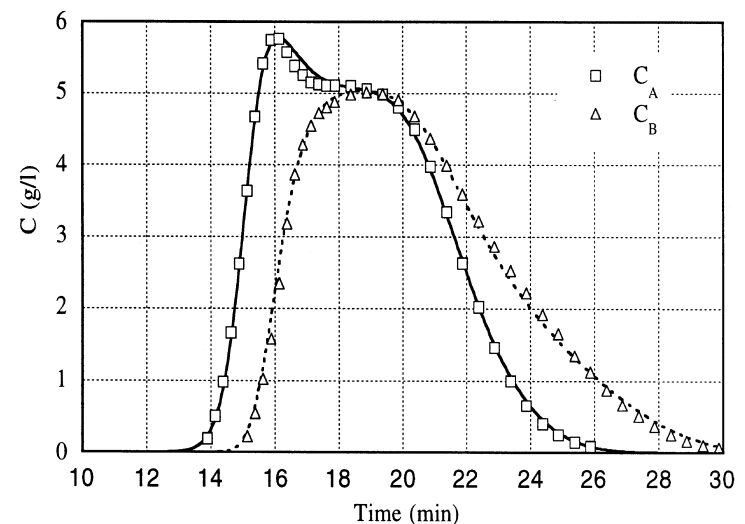

Fig. 5. Chromatographic response to a feed pulse. Comparison between experimental (points) and model (lines) results. (Pulse: 5 $\mathrm{g} / 1$ each enantiomer, during $7.5 \mathrm{~min}$; flow-rate: $5 \mathrm{ml} / \mathrm{min}$ ). Squares and solid lines for the less retained component (A), triangles and dashed lines for the more retained component (B).

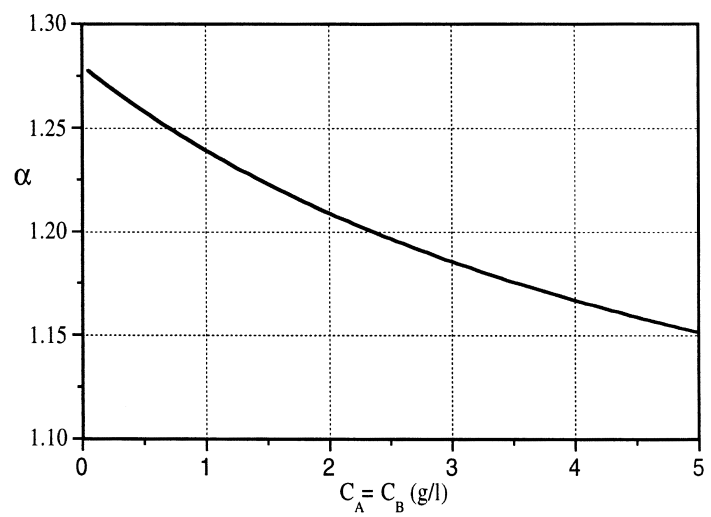

Fig. 6. Influence of the enantiomer concentration on the selectivity factor (racemic mixtures).

\section{Modeling of a SMB system}

\subsection{SMB strategies of modeling}

Different models to predict the performance of a SMB separation process have been proposed in the literature, with reasonable agreement with experimental results. These models can be classified according to the description of the fluid flow as continuous flow models (plug or axial dispersion flow) or as mixing cell models. Otherwise, some authors considered mass transfer rate inside particles 
described by the linear driving force approximation, while others used the equilibrium theory and neglected mass transfer resistances and axial mixing. Some references about the SMB strategies of modeling can be found elsewhere [39,49,50] and are summarized in Table 3.

Two main strategies can be carried out to model a SMB system: one, the SMB model, that considers the real shift of the injection and collection points, the other, the TMB (true moving bed) model, that considers liquid and solid flow in opposite directions. The predictions of these two models were compared in terms of steady-state performance and the influence of the degree of subdivision of the bed in the SMB model predictions was also analyzed and compared with the TMB performance. Complete studies, with comparison between experimental and model results, can be found elsewhere [39,68-73]. The main conclusion of these studies is that the deviations between TMB and SMB predictions (averaged over a switch time interval) decrease as the degree of subdivision of the bed increases. For practical proposes, optimization and choice of SMB configuration (length of each section) can be safely carried out on the basis of analogy with TMB modeling.

Although transient evolution of the SMB and TMB approaches are different, they have similar steady-state performances. Since, for practical proposes, the primary objective is to characterize steady-state performance, one can simulate and obtain the optimum operating conditions for the SMB using the steady-state TMB model. Thereby, the problem consisting in a PDEs system can be reduced to an ODEs system, which requires lower computing times.

The package developed for the steady-state TMB model considers axial dispersion flow for the bulk
Table 4

Model equations for the steady-state TMB model

Mass balance in a volume element of the bed $j$ :

$D_{\mathrm{L}_{j}} \frac{\mathrm{d}^{2} c_{i j}}{\mathrm{~d} z^{2}}-v_{j} \cdot \frac{\mathrm{d} c_{i j}}{\mathrm{~d} z}-\frac{(1-\varepsilon)}{\varepsilon} \cdot k\left(q_{i j}^{*}-q_{i j}\right)=0$

Mass balance in the particle:

$u_{\mathrm{s}} \cdot \frac{\mathrm{d} q_{i j}}{\mathrm{~d} z}+k\left(q_{i j}^{*}-q_{i j}\right)=0$

Boundary conditions for section $j$ :

$z=0: \quad c_{i j}-\frac{D_{\mathrm{L}_{j}}}{v_{j}} \cdot \frac{\mathrm{d} c_{i j}}{\mathrm{~d} z}=c_{i j, 0}$

where $c_{i j, 0}$ is the inlet concentration of species $i$ in section $j$.

$z=L_{j}: \quad c_{i j}=c_{i j+1,0}$ for extract and raffinate nodes

$c_{i j}=\frac{v_{\mathrm{I}}}{v_{\mathrm{IV}}} \cdot c_{i j+1,0}$ for the eluent node

$c_{i j}=\frac{v_{\mathrm{III}}}{v_{\mathrm{II}}} \cdot c_{i j+1,0}-\frac{v_{\mathrm{F}}}{v_{\mathrm{II}}} \cdot c_{i}^{\mathrm{F}}$ for the feed node

and

$q_{i j}=q_{i j+1,0}$

Global balances:

$v_{\mathrm{I}}=v_{\mathrm{IV}}+v_{\mathrm{E}}$ eluent node

$v_{\mathrm{II}}=v_{\mathrm{I}}-v_{\mathrm{X}}$ extract node

(10a)

$v_{\mathrm{III}}=v_{\mathrm{II}}+v_{\mathrm{F}}$ feed node

(10b)

$v_{\mathrm{IV}}=v_{\mathrm{III}}-v_{\mathrm{R}}$ raffinate node

Multicomponent adsorption equilibrium isotherm:

$q_{\mathrm{A} j}^{*}=f_{\mathrm{A}}\left(c_{\mathrm{A} j}, c_{\mathrm{B} j}\right)$ and $q_{\mathrm{B} j}^{*}=f_{\mathrm{B}}\left(c_{\mathrm{A} j}, c_{\mathrm{B} j}\right)$

In the above equations, $i=\mathrm{A}, \mathrm{B}$ refers to the species in the mixture, and $j=\mathrm{I}$, II, III, IV is the section number.

fluid phase and the linear driving force (LDF) approximation is used to describe the intraparticle mass transfer rate. The model can handle any kind of adsorption isotherm. Model equations for the steadystate TMB model are summarized in Table 4 with

Table 3

Modeling strategies of SMB chromatographic processes

\begin{tabular}{lll}
\hline Modeling strategy & Model description & Ref. \\
\hline \multirow{2}{*}{ TMB } & Equilibrium theory & {$[51-57]$} \\
& Mixing cell model & {$[58,59]$} \\
& Finite mass transfer rate & {$[49,60-66]$} \\
SMB & & {$[67,68]$} \\
& Equilibrium-dispersion model & {$[69,70]$} \\
& Mixing cell model & {$[39,60,64,65,71-77]$} \\
\hline
\end{tabular}


the boundary conditions, as well as with the necessary mass balances at the nodes between each section. The resulting model parameters are: $(1-\varepsilon) /$ $\varepsilon$, the ratio between solid and fluid volumes; $\gamma_{j}=v_{j} /$ $u_{\mathrm{s}}$, the ratio between fluid and solid velocities; $\mathrm{Pe}_{j}$, Peclet number; $\alpha_{j}=k L_{j} / u_{\mathrm{s}}$, number of mass transfer units.

Model equations were numerically solved by using the COLNEW software [78] which implements a finite-element collocation technique for mixed-order systems of linear or nonlinear boundary-value ordinary differential equations.

\subsection{Prediction of the separation regions and process performance}

To achieve the desired separation in a TMB unit (Fig. 7), some constraints have to be met to recover the less adsorbed component $\mathrm{A}$ in the raffinate and the more retained component $\mathrm{B}$ in the extract. These constraints are expressed in terms of the net fluxes of the two components in each zone. In zone I the heavier species B must move upwards, in zones II and III the light species must move upwards, while the heavier must move downwards, and in zone IV the net flux of $\mathrm{A}$ has to be downwards, i.e.,

$$
\begin{aligned}
\frac{Q_{\mathrm{I}} c_{\mathrm{BI}}}{Q_{\mathrm{S}} q_{\mathrm{BI}}} & >1 ; \frac{Q_{\mathrm{II}} c_{\mathrm{AII}}}{Q_{\mathrm{S}} q_{\mathrm{AII}}}>1 \text { and } \frac{Q_{\mathrm{II}} c_{\mathrm{BII}}}{Q_{\mathrm{S}} q_{\mathrm{BII}}}<1 ; \frac{Q_{\mathrm{III}} c_{\mathrm{AIII}}}{Q_{\mathrm{S}} q_{\mathrm{AIII}}} \\
& >1 \text { and } \frac{Q_{\mathrm{III}} c_{\mathrm{BIII}}}{Q_{\mathrm{S}} q_{\mathrm{BIII}}}<1 ; \frac{Q_{\mathrm{IV}} c_{\mathrm{AIV}}}{Q_{\mathrm{S}} q_{\mathrm{AIV}}}<1
\end{aligned}
$$

where $Q_{\mathrm{I}}, Q_{\mathrm{II}}, Q_{\mathrm{III}}, Q_{\mathrm{IV}}$ are the volumetric liquid flow-rates in the various zones of the TMB, $Q_{\mathrm{S}}$ is the solid flow-rate, $c_{\mathrm{A} j}, c_{\mathrm{B} j}$ are the concentrations of species $\mathrm{A}$ and $\mathrm{B}$ in the liquid phase and $q_{\mathrm{A} j}, q_{\mathrm{B} j}$ are the adsorbed concentrations of components $\mathrm{A}$ and $\mathrm{B}$, in zone $j$.

The same constraints can be expressed alternative-

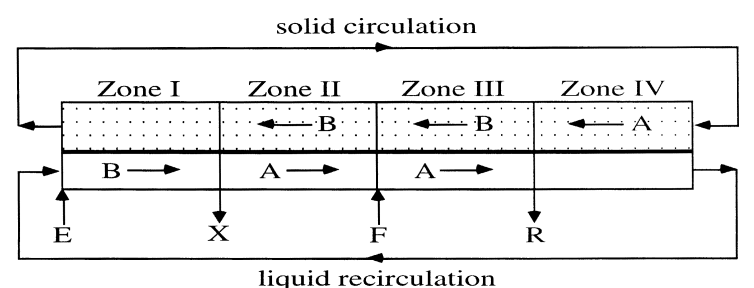

Fig. 7. Schematic diagram of the four-section TMB. ly in terms of fluid and solid velocities. Defining the dimensionless parameter:

$\Gamma_{i j}=\gamma_{j} \cdot \frac{\varepsilon}{(1-\varepsilon)} \cdot \frac{c_{i j}}{q_{i j}}$

where $\gamma_{j}=v_{j} / u_{\mathrm{s}}$ is the ratio between fluid and solid velocities in zone $j$ and $\varepsilon /(1-\varepsilon)$ is the ratio between fluid and solid volumes, the constraints defined by Eq. (12) become:

$$
\begin{aligned}
\Gamma_{\mathrm{BI}} & >1 ; \Gamma_{\mathrm{AII}}>1 \text { and } \Gamma_{\mathrm{BII}}<1 ; \Gamma_{\mathrm{AIII}}>1 \text { and } \Gamma_{\mathrm{BIII}} \\
& <1 ; \Gamma_{\mathrm{AIV}}<1
\end{aligned}
$$

Considering that the separation system is fully characterized, i.e., adsorbent and mobile phases, column dimensions, SMB configuration and feed concentration, the optimization of the TMB operating conditions consists in setting the liquid flowrates in each zone and the solid flow-rate as well. The resulting optimization problem with five variables will be certainly tedious and difficult to implement.

Fortunately, the optimization problem can be simplified if we take into account the functions of the different zones of a TMB system. Zone I, located between the eluent and extract nodes, must provide the complete regeneration of the adsorbent phase, so the solid coming out this zone is recycled to zone IV completely clean of the two components. In other words, both components A and B must move upwards, following the liquid phase. Because component $\mathrm{B}$ is the more retained species, we have to consider only the constraint considering this component; i.e., if the constraint is fulfilled for species B, the constraint considering the less retained component A will be always met. On the other hand, the liquid flow-rate in zone $\mathrm{I}$ is the highest flow-rate in a four-section TMB system. For practical proposes, this flow-rate will be limited by the system pressuredrop. Taking into account the maximum system pressure-drop accepted and the constraint considering the more retained component in zone I, we can fix the liquid flow-rate in this zone, as well as the switch time period for the SMB system (related to the TMB solid flow-rate). In this work, the maximum SMB liquid flow-rate allowed was fixed in $31 \mathrm{ml} /$ $\min$.

The worst situation concerning the constraint in 
zone I appears when dealing with low concentrations of the two enantiomers because it leads to bigger retention times. Since the function of zone I is to completely regenerate the adsorbent phase, at the beginning of this zone, concentrations of both enantiomers must be the lowest possible. Hence, the choice of the switch time period must be done taking into account the initial slope of the proposed isotherm. The linear retention time of a component $i$ in zone $j$ is given by the following equation:

$t_{i j}=\frac{\varepsilon V_{\mathrm{c}}}{Q_{j}^{*}} \cdot\left(1+\frac{1-\varepsilon}{\varepsilon} \cdot K_{i}\right)$

where $K_{i}$ is the initial slope of the isotherm for component $i$. Considering that the SMB system in study is constituted by $9.9 \mathrm{~cm} \times 2.6 \mathrm{~cm}$ columns $\left(V_{\mathrm{c}}=52.56 \mathrm{ml}\right), \varepsilon=0.4, K_{\mathrm{B}}=m+Q b_{\mathrm{B}}=2.543$, and using the maximum flow-rate allowed in this SMB system, $Q_{\mathrm{I}}^{*}=31 \mathrm{ml} / \mathrm{min}$, the retention time of the more retained component in zone $\mathrm{I}$ is $t_{\mathrm{BI}}=3.27 \mathrm{~min}$. Hence, the switch time period for the SMB operation must be greater than the retention time of the more retained component in zone I, if we want to fulfil the constraint previously presented for this zone. The value chosen for the switch time period was $t^{*}=3.3$ min, which corresponds to a TMB solid flow-rate of $Q_{\mathrm{s}}=(1-\varepsilon) V_{\mathrm{c}} / t^{*}=9.56 \mathrm{ml}$ of $\mathrm{solid} / \mathrm{min}$.

The function of zone IV, located between the raffinate and eluent nodes, is to regenerate the liquid phase, so that it can be recycled to zone I as pure eluent. In other words, both components $\mathrm{A}$ and $\mathrm{B}$ must move downwards, following the solid-phase. Because component $\mathrm{A}$ is the less retained species, we have to consider only the constraint considering this component; i.e., if the constraint is fulfilled for species $\mathrm{A}$, the constraint considering the more retained component $\mathrm{B}$ will be always met.

The evaluation of the retention times in zone IV and the choice of the liquid flow-rate for this zone (the recycling flow-rate) are not straightforward as it was for zone I. The worst situation, concerning the constraint in zone IV, appears when dealing with non-linear behaviour because it leads to lower retention times and we must prevent that the less retained component reaches the end of this zone before the jump of the inlet/outlet lines in the SMB operation. Since the switch time period was already chosen and, in a situation of enantiomer separation, the concentration of the more retained component along the zone IV is near zero, we propose the choice of the liquid flow-rate in zone IV by using the following equation:

$Q_{\mathrm{IV}}^{*}=\frac{\varepsilon V_{\mathrm{c}}}{t^{*}} \cdot\left(1+\frac{1-\varepsilon}{\varepsilon} \cdot \frac{\Delta q_{\mathrm{A}}^{* \mathrm{~F}}}{\Delta C_{\mathrm{A}}^{\mathrm{F}}}\right)$

where $\Delta q_{\mathrm{A}}^{* \mathrm{~F}} / \Delta C_{\mathrm{A}}^{\mathrm{F}}$ is the slope of the chord linking points $\left(C_{\mathrm{A}}^{\mathrm{F}}, q_{\mathrm{A}}^{* \mathrm{~F}}\right)$ and $(0,0)$ with $C_{\mathrm{B}}=0$. Considering that feed concentration used in this work is $5 \mathrm{~g} / 1$ of each enantiomer and $\Delta q_{\mathrm{A}}^{* \mathrm{~F}} / \Delta C_{\mathrm{A}}^{\mathrm{F}}=m+Q b_{\mathrm{A}} /(1+$ $b_{\mathrm{A}} C_{\mathrm{A}}^{\mathrm{F}}$ ) $=1.794$, Eq. (16) gives $Q_{\mathrm{IV}}^{*}=23.51 \mathrm{ml} / \mathrm{min}$. The choice of the liquid flow-rate in zone IV will be discussed later in this paper.

The original optimization problem with five variables was, by choosing the liquid flow-rate in zone I by pressure-drop limitations and following Eqs. (15) and (16) to evaluate the switch time period and the recycling flow-rate, reduced to a two-variable optimization problem: the choice of liquid flow-rates in the two central zones.

The conditions for enantiomer separation can be defined alternatively in terms of the $\gamma_{j}$ model parameters, which are directly related with the TMB (SMB) operating variables (fluid and solid velocities in the four zones of the TMB unit). Since the $\gamma$ values for zones I and IV were already fixed preventing that constraints concerning these zones were fulfilled, a region for enantiomer separation can be defined in a $\gamma_{I I I}-\gamma_{\text {II }}$ plane. This $\gamma_{\text {III }}-\gamma_{\text {II }}$ plot is an important tool in the choice of best operating conditions. To characterize the steady-state SMB performance four process parameters are defined: purity, recovery, solvent consumption and adsorbent productivity. For the case of a binary separation in which the less retained species $\mathrm{A}$ is recovered in the raffinate and the more retained component $\mathrm{B}$ is recovered in the extract, process performance parameters are defined in Table 5.

The conditions for complete enantiomer separation were analyzed in the frame of the equilibrium theory, where mass transfer resistances and axial dispersion are neglected, by Morbidelli and co-workers $[79,80]$.

In this work, we use the steady-state TMB model presented before in Table 4 which considers mass transfer resistance and axial dispersion. The region 
Table 5

SMB performance criteria

\begin{tabular}{llc}
\hline Performance parameter & Extract & Raffinate \\
\hline Purity (\%) & $\mathrm{PUX}=100 C_{\mathrm{B}}^{\mathrm{X}} /\left(C_{\mathrm{A}}^{\mathrm{X}}+C_{\mathrm{B}}^{\mathrm{X}}\right)$ & $\mathrm{PUR}=100 C_{\mathrm{A}}^{\mathrm{R}} /\left(C_{\mathrm{A}}^{\mathrm{R}}+C_{\mathrm{B}}^{\mathrm{R}}\right)$ \\
Recovery (\%) & $\mathrm{RCX}=100 Q_{\mathrm{X}} C_{\mathrm{B}}^{\mathrm{X}} / Q_{\mathrm{F}} C_{\mathrm{B}}^{\mathrm{F}}$ & $\mathrm{RCR}=100 Q_{\mathrm{R}} C_{\mathrm{A}}^{\mathrm{R}} / Q_{\mathrm{F}} C_{\mathrm{A}}^{\mathrm{F}}$ \\
Solvent consumption $(1 / \mathrm{g})$ & $\mathrm{SC}=\left(Q_{\mathrm{E}}+Q_{\mathrm{F}}\right) /\left[Q_{\mathrm{F}}\left(C_{\mathrm{A}}^{\mathrm{F}}+C_{\mathrm{B}}^{\mathrm{F}}\right)\right]$ & $\mathrm{PR}=Q_{\mathrm{F}}\left(C_{\mathrm{A}}^{\mathrm{F}}+C_{\mathrm{B}}^{\mathrm{F}}\right) / V_{\mathrm{T}}$ \\
Productivity (g/day 1 of bed) & & \\
\hline
\end{tabular}

for enantiomer separation is then defined by resolving numerically the ODEs system with the COLNEW software. Table 6 summarizes the SMB operating conditions (and equivalent TMB conditions) used in the design of the $\gamma_{\text {III }}-\gamma_{\text {II }}$ plot.

Fig. 8 presents the separation region obtained for the chiral epoxide system. Inside the region limited by open squares, triangles and closed squares, both extract and raffinate purities are at least 90, 95 and 99\%, respectively. The thin line in Fig. 8 has two branches. The diagonal $\gamma_{\text {III }}=\gamma_{\text {II }}$ corresponds to zero feed flow-rate; therefore, $\gamma_{\text {III }}$ must be higher than $\gamma_{\text {II }}$. The horizontal branch $\gamma_{\mathrm{III}} \approx 2.69$ corresponds to zero raffinate flow-rate $\left(\gamma_{\mathrm{III}}=\gamma_{\mathrm{IV}}\right)$.

The influence of the mass transfer resistance in the separation region is analyzed in Fig. 9. This figure presents and compares the separation region $(90 \%$ purity criteria) obtained for $k=0.4 \mathrm{~s}^{-1}$ (open squares) and $k=0.1 \mathrm{~s}^{-1}$ (closed squares). It can be concluded that mass transfer resistance reduces the region of separation of both enantiomers and that the region obtained for a lower mass transfer coefficient lies inside the region obtained when mass transfer resistance is not so important. Hence, the choice of the best operating conditions must take into account the mass transfer resistance phenomenon.

For practical purposes, it is desirable to work with

Table 6

Operating conditions and model parameters for the $\gamma_{\text {III }}-\gamma_{\text {II }}$ plot

\begin{tabular}{|c|c|}
\hline SMB & Equivalent TMB \\
\hline $\begin{array}{l}\text { Column diameter: } D_{\mathrm{c}}=2.6 \mathrm{~cm} \\
\text { Column length: } L_{\mathrm{c}}=9.9 \mathrm{~cm} \\
\text { Configuration: } 2 \text { columns per zone }\end{array}$ & Zone length: $L_{j}=2 L_{\mathrm{c}}=19.8 \mathrm{~cm}$ \\
\hline Bed porosity: $\varepsilon=0.4$ & Solid flow-rate: $Q_{\mathrm{s}}=(1-\varepsilon) V_{\mathrm{c}} / t^{*}=9.56 \mathrm{ml} / \mathrm{min}$ \\
\hline $\begin{array}{l}\text { Peclet number: } \mathrm{Pe}=1000 \\
\text { Feed concentration: } C_{\mathrm{A}}^{\mathrm{F}}=C_{\mathrm{B}}^{\mathrm{F}}=5 \mathrm{~g} / 1 \\
\text { Switch time period: } t^{*}=3.3 \text { min }\end{array}$ & Peclet number: $\mathrm{Pe}_{j}=2 \mathrm{Pe}=2000$ \\
\hline $\begin{array}{l}\text { Flow-rate in zone I: } Q_{\mathrm{I}}^{*}=31 \mathrm{ml} / \mathrm{min} \\
\text { Flow-rate in zone IV: } Q_{\mathrm{IV}}^{*}=23.51 \mathrm{ml} / \mathrm{min}\end{array}$ & $\begin{array}{l}\text { Flow-rate in zone I: } Q_{\mathrm{I}}=Q_{\mathrm{I}}^{*}-Q_{\mathrm{s}} \varepsilon /(1-\varepsilon)=24.63 \mathrm{ml} / \mathrm{min} \\
\text { Flow-rate in zone IV: } Q_{\mathrm{IV}}^{*}=Q_{\mathrm{IV}}^{*}-Q_{\mathrm{s}} \varepsilon /(1-\varepsilon)=17.14 \mathrm{ml} / \mathrm{min}\end{array}$ \\
\hline
\end{tabular}

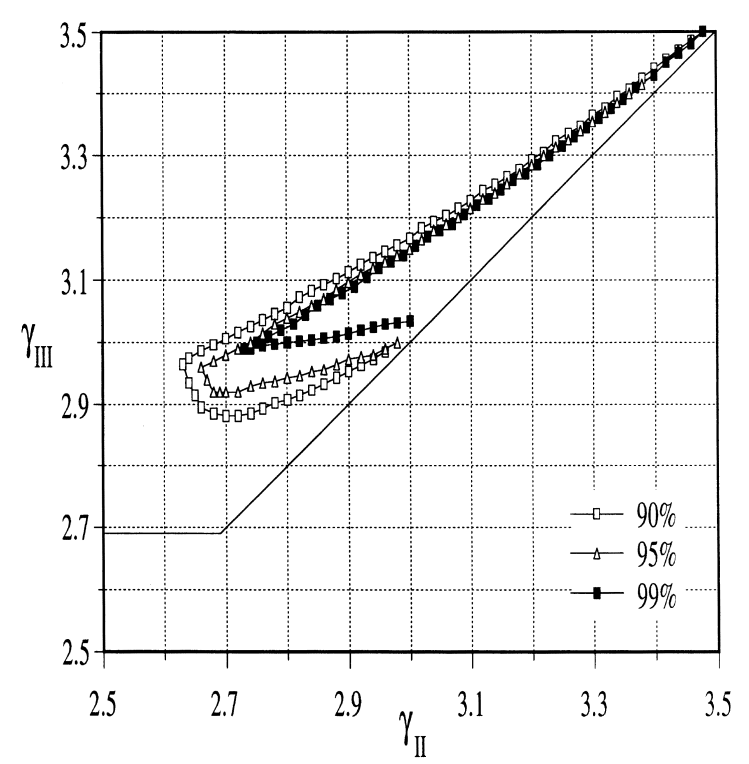

Fig. 8. Separation regions in a $\gamma_{I I I}-\gamma_{I I}$ plot for $90 \%$ (open squares), 95\% (triangles) and 99\% (closed squares) purity criteria. Mass transfer coefficient, $k=0.4 \mathrm{~s}^{-1}$.

variables directly related with the SMB unit. Instead of presenting the separation region in a $\gamma_{\text {III }}-\gamma_{\text {II }}$ plot, we can report the same information in a $Q_{\mathrm{X}}$ versus $Q_{\mathrm{F}}$ plot. Eqs. (17) and (18) present the conversion 


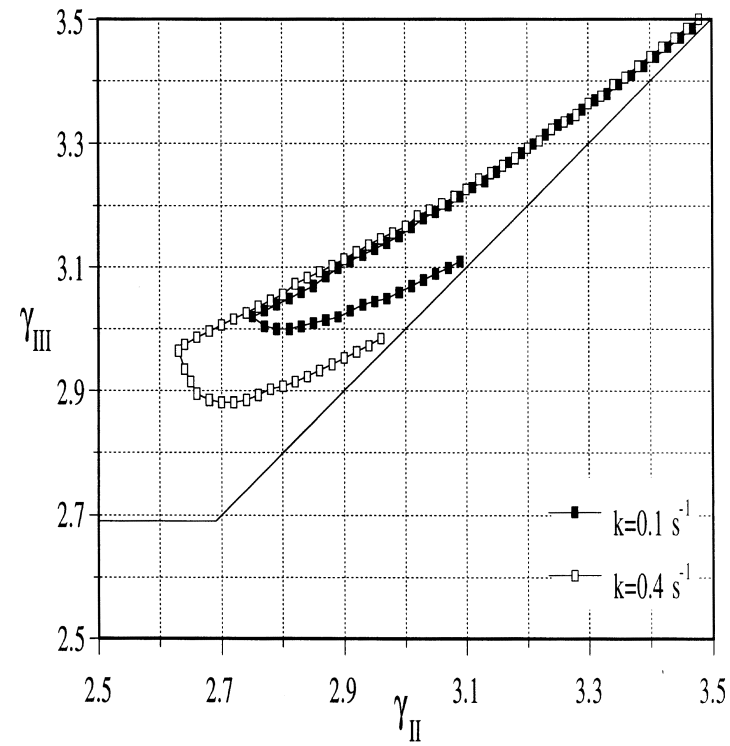

Fig. 9. Influence of the mass transfer resistance on the separation region: $\gamma_{\text {III }}-\gamma_{\text {II }}$ plot for a $90 \%$ purity criteria (open squares for mass transfer coefficient, $k=0.4 \mathrm{~s}^{-1}$; closed squares for $k=0.1$ $\left.\mathrm{s}^{-1}\right)$.

rules between the TMB operating conditions and feed and extract flow-rates:

$Q_{\mathrm{F}}=\frac{\varepsilon}{1-\varepsilon} \cdot\left(\gamma_{\mathrm{III}}-\gamma_{\mathrm{II}}\right) Q_{\mathrm{s}}$

$Q_{\mathrm{X}}=\frac{\varepsilon}{1-\varepsilon} \cdot\left(\gamma_{\mathrm{I}}-\gamma_{\mathrm{II}}\right) Q_{\mathrm{s}}$

Since the liquid flow-rates in zones I and IV are constant in this study, the eluent flow-rate is also constant and equal to $Q_{\mathrm{I}}^{*}-Q_{\mathrm{IV}}^{*}=Q_{\mathrm{I}}-Q_{\mathrm{IV}}=7.49$ $\mathrm{ml} / \mathrm{min}$. The raffinate flow-rate can be evaluated by $Q_{\mathrm{R}}=Q_{\mathrm{E}}+Q_{\mathrm{F}}-Q_{\mathrm{X}}$. Fig. 10 presents the same separation regions defined in Fig. 9, for $k=0.4 \mathrm{~s}^{-1}$ (open squares) and $k=0.1 \mathrm{~s}^{-1}$ (closed squares), following a $90 \%$ purity criteria.

It is interesting to observe what happens when we travel along a vertical line in Fig. 10, i.e., for a fixed feed flow-rate, how the system behaves when extract flow-rate changes. The results are presented in Fig. 11 , where the purity and recovery performance parameters are evaluated in function of the extract flow-rate variation and for a constant feed flow-rate of $1.25 \mathrm{ml} / \mathrm{min}$. In these figures we can observe three different regions: a central region where sepa-

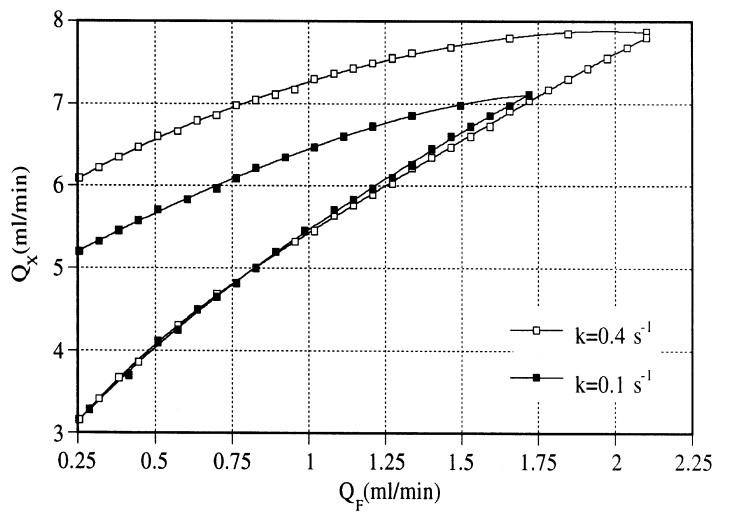

Fig. 10. Influence of the mass transfer resistance on the separation region: $Q_{\mathrm{X}}$ versus $Q_{\mathrm{F}}$ plot for a $90 \%$ purity criteria (open squares for mass transfer coefficient, $k=0.4 \mathrm{~s}^{-1}$; closed squares for $k=0.1$ $\left.\mathrm{s}^{-1}\right)$.
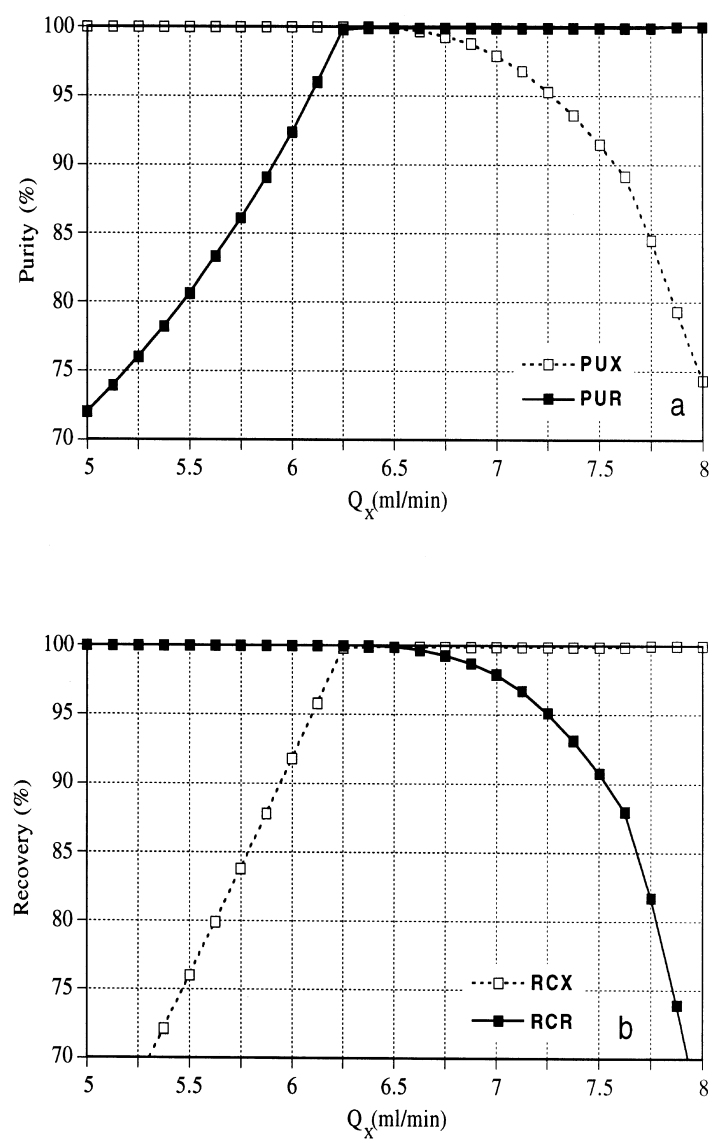

Fig. 11. Effect of the extract flow-rate on the purity (a) and recovery (b) parameters (same conditions as in Table 6 and $k=0.4$ $\left.\mathrm{s}^{-1}, Q_{\mathrm{E}}=7.49 \mathrm{ml} / \mathrm{min}, Q_{\mathrm{F}}=1.25 \mathrm{ml} / \mathrm{min}, Q_{\mathrm{R}}=Q_{\mathrm{E}}+Q_{\mathrm{F}}-Q_{\mathrm{X}}\right)$. 
ration of both enantiomers is achieved with also high recoveries, and two adjacent regions where only one outlet is pure. In conclusion, the optimum extract flow-rate can be chosen so that both extract and raffinate purities are high or, alternatively, the extract purity equals the raffinate purity. Since the objective of the SMB operation is to obtain the two pure enantiomers, the path of equal purities is the optimum trajectory that must be followed. For a given feed flow-rate, the SMB optimization can be carried out by minimizing the following objective function:

$\operatorname{minimize} \Phi_{1}=(\mathrm{PUX}-\mathrm{PUR})^{2}$

The minimization was implemented by using the ZXMIN routine from IMSL [81], which uses a quasi-Newton method to find the minimum of the $\Phi_{1}$ function. The optimization variable can be, for example, $Q_{\mathrm{II}}^{*}$, the liquid flow-rate in zone II. The liquid flow-rate in zone III will be evaluated by $Q_{\mathrm{III}}^{*}=Q_{\mathrm{II}}^{*}+Q_{\mathrm{F}}$.

The results obtained are presented in Fig. 12. Fig. 13 presents the purities of both extract and raffinate obtained with the optimization procedure proposed in Eq. (19). It should be pointed out that, when racemic mixtures are fed into a SMB unit, if extract and raffinate purities are equal, recoveries of both extract and raffinate are also equal and with the same value of the purity obtained. Observing Fig. 13, we can conclude that, for the conditions presented in Table 6 , the purity of the outlet streams begins to decline

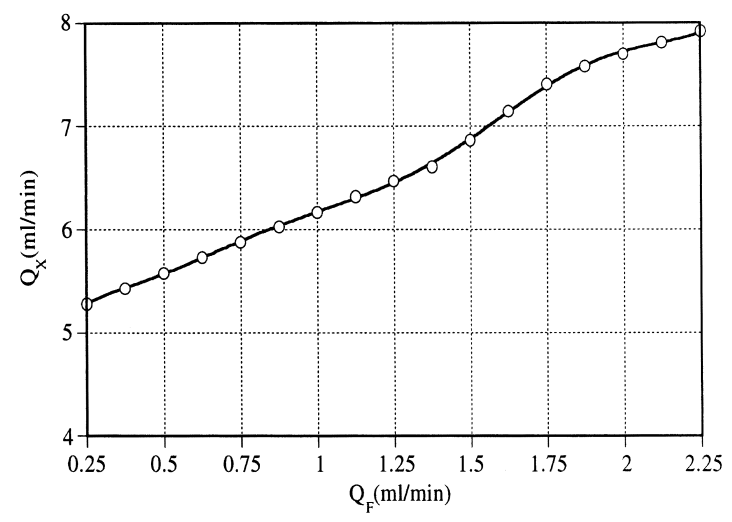

Fig. 12. Optimum extract and feed flow-rates: path of equal raffinate and extract purities (same conditions as in Table 6 and $k=0.4 \mathrm{~s}^{-1}, Q_{\mathrm{E}}=7.49 \mathrm{ml} / \mathrm{min}, Q_{\mathrm{R}}=Q_{\mathrm{E}}+Q_{\mathrm{F}}-Q_{\mathrm{X}}$.

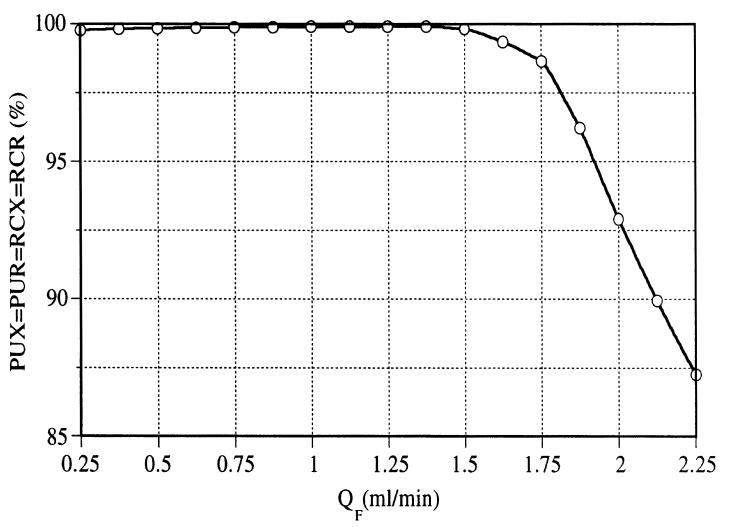

Fig. 13. Optimum purities and recoveries as a function of the feed flow-rate (same conditions as in Fig. 12).

for feed flow-rates greater than $1.5 \mathrm{ml} / \mathrm{min}$. For higher feed flow-rates, complete separation of the two enantiomers will need a higher eluent flow-rate, which will violate the constraint for maximum liquid flow-rate in zone I imposed by pressure-drop limitations. In fact, according to Eq. (17) and in order to increase the feed flow- rate at constant $\left(\gamma_{\mathrm{III}}-\gamma_{\mathrm{II}}\right)$, the solid flow-rate has to be increased. This means that the switch time period has to be decreased and, according to Eq. (15), the flow-rate in zone I will be increased. Since the flow-rate in zone IV is fixed, this means that the eluent flow-rate will increase.

Fig. 14 presents the solvent consumption and adsorbent productivity obtained as a function of the feed flow-rate. Of course, this figure should not be

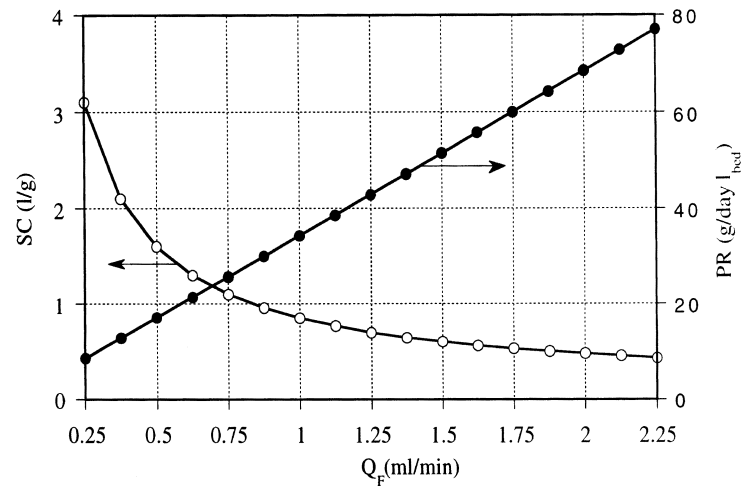

Fig. 14. Solvent consumption (open circles) and adsorbent productivity (closed circles), obtained for the equal purities optimization procedure, as a function of the feed flow-rate (same conditions as in Fig. 12). 
used without looking for Fig. 13: the increase of the feed flow-rate leads to better solvent consumption and productivity performances, but it is followed by a decrease in both purities and recoveries of extract and raffinate. Furthermore, the higher the feed flowrate, the smaller the range of extract flow-rates that leads to both enantiomer separation (see Fig. 10). This means that the process robustness also decreases with the increase of the feed flow-rate.

In conclusion, the set of Figs. 10,12 and 13 provide a practical tool for choosing the better SMB operating conditions as a function of the feed flowrate. The optimum will result from a trade-off between solvent consumption and adsorbent productivity, purity and recovery requirements, and system robustness. The equal purities optimization procedure proposed by Eqs. (15), (16), (19) provides a simple tool for choosing the best SMB operating conditions.

We will discuss now the choice of the recycling flow-rate made following Eq. (16). We decided to extend the optimization procedure to the choice of the liquid flow-rate in zone IV. The optimization variables will be $Q_{\mathrm{II}}^{*}$ and $Q_{\mathrm{IV}}^{*}$. The liquid flow-rate in zone III will be evaluated by $Q_{\mathrm{III}}^{*}=Q_{\mathrm{II}}^{*}+Q_{\mathrm{F}}$. The objective of the optimization procedure is now not only to follow the path of equal extract and raffinate purities, but also to minimize the solvent consumption. It should be pointed out that, since the recycling flow-rate, $Q_{\mathrm{IV}}^{*}$, is an optimization variable, the eluent flow-rate is no longer constant. A higher recycling flow-rate will give a lower eluent flow-rate and, consequently, a lower solvent consumption. Nevertheless, we imposed that the purity of outlet streams did not decrease from the value obtained with the recycling flow-rate evaluated by using Eq. (16) $\left(Q_{\text {IV }}^{*}=23.51 \mathrm{ml} / \mathrm{min}\right)$. For a given feed flow-rate, the optimization objective is now:

minimize $\Phi_{2}=\mathrm{SC}+(\mathrm{PUX}-\mathrm{PUR})^{2}$

Fig. 15 show the results obtained in terms of the optimum recycling flow-rate (Fig. 15) and eluent and extract flow-rates (Fig. 15). The raffinate flow-rate can be evaluated by $Q_{\mathrm{R}}=Q_{\mathrm{E}}+Q_{\mathrm{F}}-Q_{\mathrm{X}}$. Fig. 16 compares the solvent consumption obtained by the two optimization procedures. As we expected, the
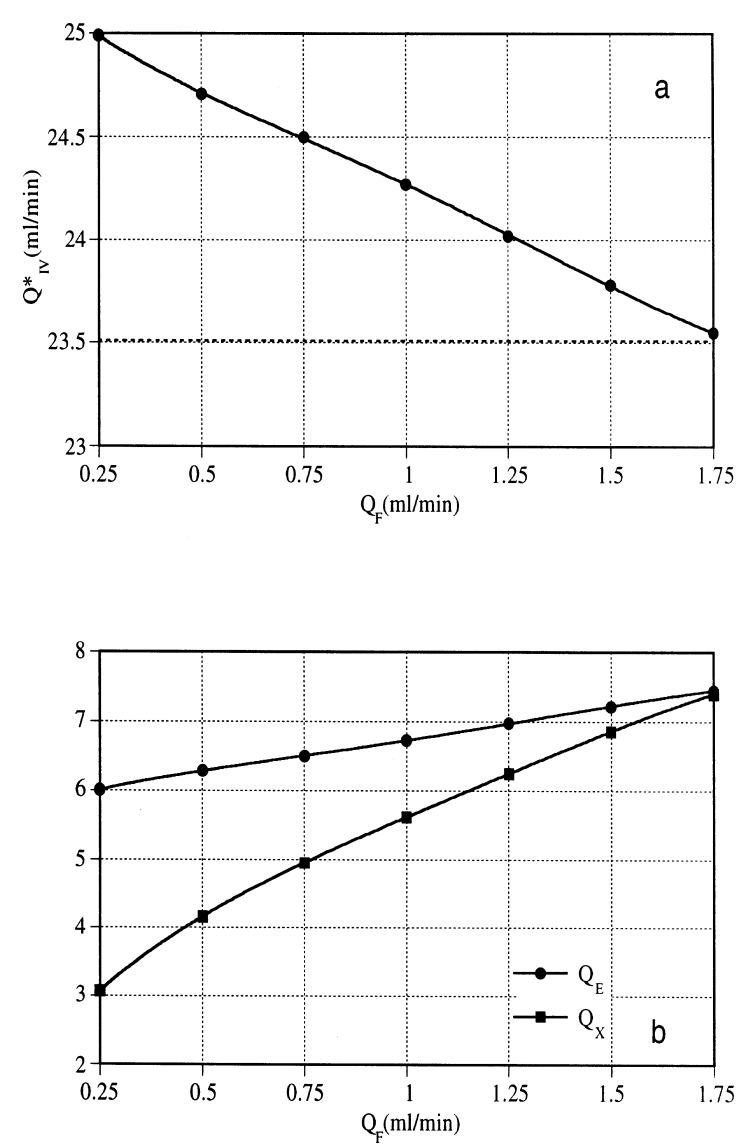

Fig. 15. Optimum operating conditions obtained for the equal purities/solvent consumption minimization procedure: (a) optimum recycling flow-rate (solid line), dashed line $Q_{\mathrm{IV}}^{*}=23.51$ $\mathrm{ml} / \mathrm{min}$; (b) optimum eluent (circles) and extract (squares) flowrates $\left(Q_{\mathrm{R}}=Q_{\mathrm{E}}+Q_{\mathrm{F}}-Q_{\mathrm{X}}\right)$.

major differences occur for low feed flow-rates. In fact, if the feed flow-rate is low, internal concentrations in the SMB unit will be lower and the non-linear adsorption behaviour will be less critical. In these situations, the recycling flow-rate evaluated by using Eq. (16) is unnecessarily low. For high feed flow-rates, small differences occur between the two optimization procedures. Since, for a given purity requirement, we should operate the SMB unit at the higher feed flow-rate possible (to increase adsorbent productivity), the optimization procedure defined by Eqs. (15), (16), (19) prove to be a simple and quick 


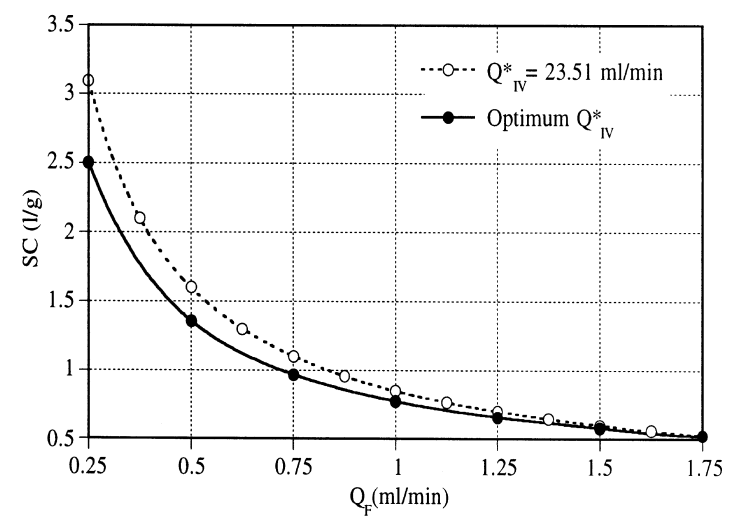

Fig. 16. Comparison between solvent consumption obtained for the equal purities optimization procedure with $Q_{\mathrm{IV}}^{*}=23.51 \mathrm{ml} /$ min (open circles) and by the equal purities/solvent consumption minimization procedure (closed circles).

optimization tool for the choice of the SMB operating conditions.

\section{Operation of the SMB pilot unit}

The operation of the SMB pilot unit (Licosep 12-26) described before was carried out for the separation of the chiral epoxide enantiomers. This separation was studied by Nicoud et al. [43] and Kusters et al. [82]. An eight-column configuration was used and the operation temperature was fixed at $25^{\circ} \mathrm{C}$. Feed concentration used was $5 \mathrm{~g} / 1$ of each enantiomer and the system pressure-drop was 15 bar at a flow-rate of $25 \mathrm{ml} / \mathrm{min}$. Table 7 presents the experimental conditions used in the SMB operation.

The internal profiles were measured using the six-port valve of the Licosep SMB pilot to withdraw
Table 8

SMB performance parameters for the three experimental runs

\begin{tabular}{lllll}
\hline$t^{*}(\min )$ & PUX $(\%)$ & PUR $(\%)$ & RCX (\%) & RCR (\%) \\
\hline 3.28 & 88.1 & 91.4 & 94.2 & 90.9 \\
3.30 & 90.0 & 91.6 & 94.5 & 90.7 \\
3.33 & 90.9 & 83.9 & 84.8 & 91.0 \\
\hline
\end{tabular}

samples from the system. The samples were collected at each half-time period and after 30 full cycles of continuous operation. The experimental performance parameters were determined by analysis of the extract and raffinate samples collected during the whole last cycle (after cyclic steady-state was achieved).

Comparing to the operating conditions used in simulation, a lower liquid flow-rate in zone I was used. Hence, we expected a lower experimental raffinate purity. Three runs were carried out to study the influence of the switch time period on the SMB performance. Table 8 presents the experimental performance parameters for the three runs. The better operation occurs for $t^{*}=3.30 \mathrm{~min}$, where purities and recoveries higher than $90 \%$ are obtained. For this run, simulation predicts PUX $=98.8$ and PUR $=$ 91.3 , i.e., a lower raffinate purity as expected. However, the experimental values presented in Table 8 also show lower extract purity. This could be eventually due to experimental conditions such as small variations in flow-rates or column packings.

Comparing the experimental performances presented in Table 8, and accordingly to simulation predictions, a lower switch time period reduces the extract purity, while a higher switch time period will reduce the raffinate purity. This can be explained looking for the constraints presented in Eq. (12).

Table 7

Experimental SMB operating conditions for the chiral epoxide system

\begin{tabular}{lll}
\hline SMB columns & Inlet/outlet flow-rates $(\mathrm{ml} / \mathrm{min})$ & Liquid flow-rates (ml/min) \\
\hline Diameter: $2.6 \mathrm{~cm}$ & $Q_{\mathrm{E}}=4.53$ & $Q_{\mathrm{I}}^{*}=27.73$ \\
Length: $9.9 \mathrm{~cm}$ & $Q_{\mathrm{X}}=4.00$ & $Q_{\mathrm{II}}^{*}=23.73$ \\
Number of columns: 8 & $Q_{\mathrm{F}}=1.52$ & $Q_{\mathrm{II}}^{*}=25.25$ \\
Configuration: $2-2-2-2$ & $Q_{\mathrm{R}}=2.05$ & $Q_{\mathrm{IV}}^{*}=23.20$ \\
\hline
\end{tabular}


Reducing the switch time period means that the solid flow-rate is increased, which will violate the constraint for the less retained component A in zone II. This means that this species will move downwards in this zone, contaminating the extract stream. On the other hand, increasing the switch time period means that the solid flow-rate is decreased, which will violate the constraint for the more retained component B in zone III. Hence, this component will move upwards in this zone and will contaminate the raffinate stream.

The adsorbent productivity for this experimental operation is $\mathrm{PR}=52 \mathrm{~g}$ of racemic mixture processed per day and per liter of bed, while the solvent consumption is $\mathrm{SC}=0.401$ of mobile phase per gram of racemic mixture processed. Comparing this last value to the one obtained by the optimization procedure, we conclude that the solvent consumption was reduced in $33 \%$. Unfortunately, this solvent saving was obtained with a significant reduction in the extract and raffinate purities. Table 9 compares the experimental results obtained for the separation of chiral epoxide enantiomers by SMB chromatography carried out by the referenced authors.

Fig. 17 show the SMB experimental internal profiles at cyclic steady-state. Simulation results are also displayed using the information on equilibrium and kinetic parameters obtained by the independent experiences described at the beginning of this paper. The agreement between model and experimental results is reasonable except for the concentration profile of the less retained component in the second zone. This discrepancy may be due to the fact that the sample is collected at the half-time period; the composition at that time can be different from the average composition in the whole switch time period. It can also be related with an inaccurate description of the competitive binary adsorption equilibrium. Nevertheless, the model predicts very well the drastic changes in the internal concentration profiles of both components in zone III, due to small changes in the switch time period.

\section{Conclusions}

A model for predicting the cyclic steady-state behaviour of the SMB chromatographic system is presented using the equivalent TMB approach. The model considers non-linear competitive adsorption isotherm, axial dispersion and the linear driving force approximation is used to describe the intraparticle mass transfer rate.

The main problem of the SMB operation consists in choosing the best solid (switch time interval) and liquid flow-rates. The SMB/TMB package is an important learning and training tool used to predict the effect of operating variables on the process performance, and so the choice of these best conditions for the SMB operation. The regions for enantiomer separation can be numerically predicted, considering dispersion and mass transfer resistances phenomena. The mass transfer resistance phenomenon affects the separation region of both enantiomers.

A simple optimization procedure is proposed based on the path of equal extract and raffinate purities. This tool for choosing the best SMB operating conditions was extensively tested for the separation of chiral epoxide enantiomers. The optimum will always result from a trade-off between solvent consumption and productivity, purity and recovery requirements, and system robustness.

The separation of chiral epoxide enantiomers was carried out in a SMB pilot unit Licosep 12-26. Purities and recoveries higher than $90 \%$ were obtained for both extract and raffinate, using a $420 \mathrm{ml}$ inventory of stationary phase. A productivity of $52 \mathrm{~g}$

Table 9

Experimental results obtained for the separation of chiral epoxide enantiomers by SMB chromatography

\begin{tabular}{lllllll}
\hline $\begin{array}{l}\text { Stationary } \\
\text { phase }\end{array}$ & $\begin{array}{l}\text { Inventory } \\
(\mathrm{ml})\end{array}$ & $\begin{array}{l}C^{\mathrm{F}} \\
(\mathrm{g} / \mathrm{l} \text { each) }\end{array}$ & $\begin{array}{l}\text { Purity } \\
(\%)\end{array}$ & $\begin{array}{l}\mathrm{SC} \\
(1 / \mathrm{g})\end{array}$ & $\begin{array}{l}\text { PR } \\
(\mathrm{g} / \text { day } 1 \text { bed })\end{array}$ \\
\hline MCTA $(25-40 \mu \mathrm{m})$ & 700 & 5 & 98 & 0.40 & 31.2 & Ref. \\
Chiralcel-OD $(20 \mu \mathrm{m})$ & 240 & 10 & $95($ e.e. $)$ & 0.25 & 47.7 & {$[43]$} \\
MCTA $(45 \mu \mathrm{m})$ & 420 & 5 & 91 & 0.40 & 52.1 & {$[82]$} \\
\hline
\end{tabular}



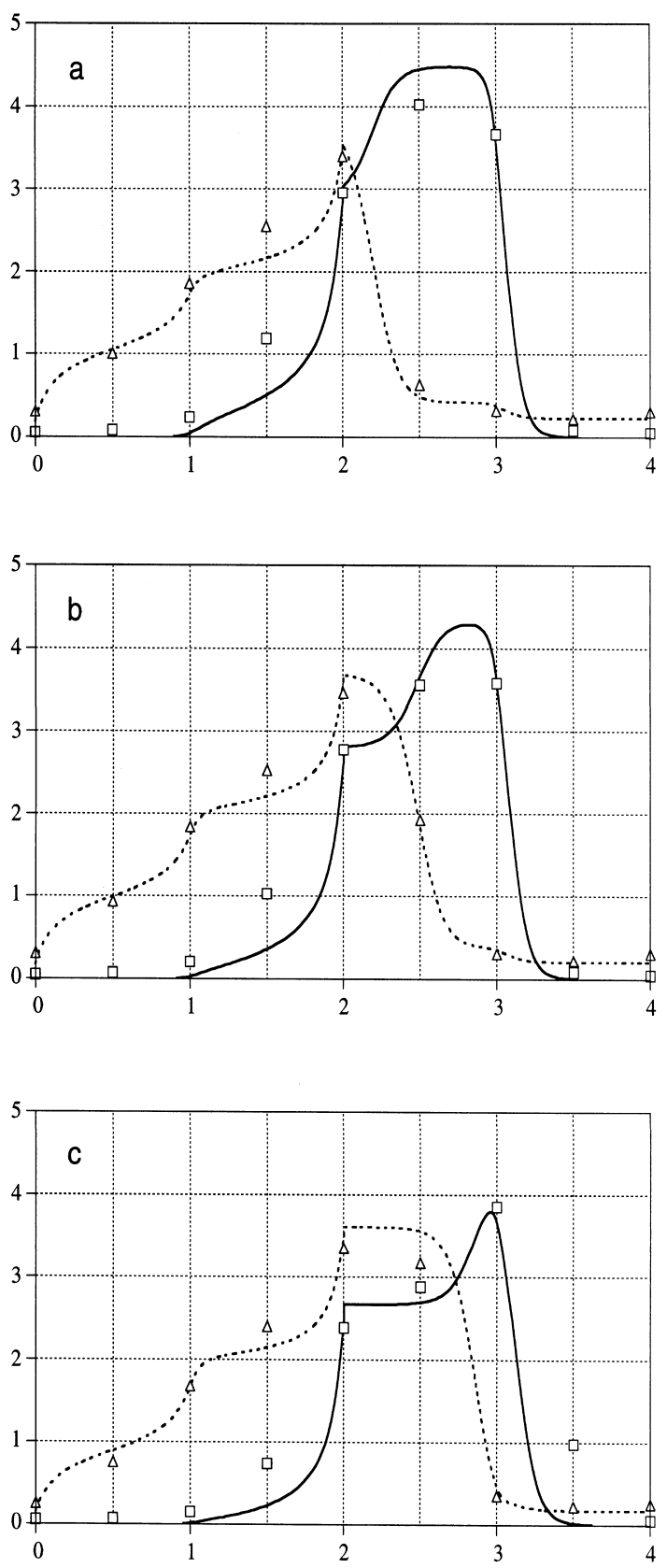

Fig. 17. Comparison between experimental (points taken at half time period in the cyclic steady-state, SMB operation) and simulated (steady state TMB operation) internal profiles: (a) switch time period, $t^{*}=3.28 \mathrm{~min}$; (b) $t^{*}=3.30 \mathrm{~min}$; (c) $t^{*}=3.33 \mathrm{~min}$. Squares and full lines represent the less retained component A; triangles and dashed lines for the more retained species B. of racemic mixture processed per day and per liter of bed was obtained. The solvent consumption was 0.41 of mobile phase per gram of racemic mixture processed. The predictions of the steady-state internal concentration profiles were carried out with reasonable agreement with experimental results.

\section{Symbols}

c Fluid phase concentration

$D_{\mathrm{L}} \quad$ Axial dispersion coefficient

$H \quad$ Plate height

$K \quad$ Initial slope of the adsorption isotherm

$k \quad$ Mass transfer coefficient

$L \quad$ Length

Pe Peclet number

PR Adsorbent productivity

PUR Raffinate purity

PUX Extract purity

$Q \quad$ Volumetric liquid flow-rate in the TMB

$Q^{*} \quad$ Volumetric liquid flow-rate in the SMB

$Q_{\text {s }} \quad$ Solid flow-rate

$q \quad$ Average adsorbed phase concentration

$q^{*} \quad$ Adsorbed concentration in equilibrium with

RCR Raffinate recovery

RCX Extract recovery

SC Solvent consumption

$t \quad$ Retention time

$t^{*} \quad$ Switch time period

$u_{\mathrm{s}} \quad$ Solid velocity

$V \quad$ Volume

$V_{\mathrm{c}} \quad$ Column volume

$V_{\mathrm{T}} \quad$ Volume of the adsorbent bed

$v \quad$ Interstitial fluid velocity

$z \quad$ Axial coordinate

\subsection{Greek symbols}

$\Gamma \quad$ Dimensionless parameter, defined in Eq. (13)

$\alpha \quad$ Number of mass transfer units

$\varepsilon \quad$ Bed porosity

$\varepsilon_{\mathrm{T}} \quad$ Total porosity

$\gamma \quad$ Ratio between fluid and solid velocities 


\subsection{Subscripts and superscripts}

$\begin{array}{ll}\text { A } & \text { Less retained component } \\ \text { B } & \text { More retained component } \\ \text { E } & \text { Eluent } \\ \text { F } & \text { Feed } \\ \text { R } & \text { Raffinate } \\ \text { X } & \text { Extract }\end{array}$

\section{Acknowledgements}

Financial support from the European Union under the BRITE-EURAM Programme (Contract No. BRE2-CT92-0337) is gratefully acknowledged. Thanks are also due to R.-M. Nicoud, J. Blehaut and F. Charton (Novasep) and J. Kinkel (Merck and Georg-Simon-Ohm Fachhochschule) for helpful discussions and preparation of the chiral packings.

\section{References}

[1] G. Hesse, R. Hagel, Chromatographia 6 (1973) 277.

[2] H. Koller, K.-H. Rimböck, A. Mannschreck, J. Chromatogr. 282 (1983) 89.

[3] G. Blaschke, J. Liq. Chromatogr. 9 (1986) 341.

[4] T. Shibata, I. Okamoto, K. Ishii, J. Liq. Chromatogr. 9 (1986) 313.

[5] E. Francotte, A. Junker-Buchheit, J. Chromatogr. 576 (1992) 1.

[6] G. Hesse, R. Hagel, Chromatographia 9 (1976) 62.

[7] E. Francotte, R. Wolf, D. Lohmann, R. Mueller, J. Chromatogr. 347 (1985) 24.

[8] R. Isaksson, P. Erlandsson, L. Hansson, A. Holmberg, S. Berner, J. Chromatogr. 498 (1990) 257.

[9] M.A. Peterson, K.B. Lipkowitz, J. Molec. Struct. (Theochem) 395-396 (1997) 411.

[10] Y. Okamoto, CHEMTECH March (1987) 176.

[11] A. Ichida, T. Shibata, in: M. Zief, L.J. Crane (Eds.), Chromatographic Chiral Separations, Marcel Dekker, New York, 1988, Ch. 9, p. 219.

[12] K. Oguni, H. Oda, A. Ichida, J. Chromatogr. A 694 (1995) 91.

[13] J. Dingenen, I. Somers, F. Pauwels, A. Van Loon, in: M. Perrut (Ed.), Proceedings of the 9th International Symposium on Preparative and Industrial Chromatography, Société Française de Chimie, Nancy, 1992, p. 359.

[14] K.-H. Rimböck, F. Kastner, A. Mannschreck, J. Chromatogr. 329 (1985) 307.

[15] M. Zief, in: M. Zief, L.J. Crane (Eds.), Chromatographic Chiral Separations, Marcel Dekker, New York, 1988, Ch. 13, p. 337.
[16] E. Francotte, in: R.-M. Nicoud (Ed.), Simulated Moving Bed: Basics and Applications, Separex and ENSIC, INPL, Nancy, 1993, p. 35.

[17] E.R. Francotte, in: S. Ahuja (Ed.), Chiral Separations Applications and Technology, American Chemical Society, Washington, DC, 1996, Ch. 10, p. 271.

[18] E. Francotte, in: H. Aboul-Enein, I. Wainer (Eds.), The Impact of Stereochemistry on Drug Development and Use (Chemical Analysis Series, Vol. 42), Wiley, New York, 1997, Ch. 23, p. 633 .

[19] D.B. Broughton, C.G. Gerhold, US Pat. 2985589 (1961).

[20] D.B. Broughton, Chem. Eng. Prog. 64 (1968) 60.

[21] D.B. Broughton, R.W. Neuzil, J.M. Pharis, C.S. Brearley, Chem. Eng. Prog. 66 (1970) 70.

[22] D.B. Broughton, Sep. Sci. Technol. 19 (1984) 723.

[23] J.A. Johnson, R.G. Kabza, in: G. Ganetsos, P.E. Barker (Eds.), Preparative and Production Scale Chromatography, Marcel Dekker, New York, 1993, Ch. 12, p. 257.

[24] R.-M. Nicoud, Simulated Moving Bed: Basics and Applications, Separex and ENSIC, INPL, Nancy, 1993.

[25] R.-M. Nicoud, Recent Advances in Industrial Chromatographic Processes, NOVASEP, Nancy, 1997.

[26] M.J. Gattuso, B. McCulloch, J.W. Priegnitz, in: Proceedings of the Chiral Europe'94 Symposium, 1994.

[27] M.J. Gattuso, B. McCulloch, D.W. House, W.M. Baumann, in: Proceedings of the Chiral USA'95 Symposium, 1995.

[28] M.J. Gattuso, B. McCulloch, D.W. House, W.M. Baumann, K. Gottschall, Pharm. Tech. Europe 8 (1996) 20.

[29] R.A. Sheldon, Chirotechnology: Industrial Synthesis of Optically Active Compounds, Marcel Dekker, New York, 1993.

[30] S.C. Stinson, Chem. Eng. News, September 27 (1993) 38.

[31] S.C. Stinson, Chem. Eng. News, September 19 (1994) 38.

[32] S.C. Stinson, Chem. Eng. News, July 17 (1995) 10.

[33] S.C. Stinson, Chem. Eng. News, October 9 (1995) 44.

[34] R.-M. Nicoud, LC·GC Int. 5 (1992) 43.

[35] B. Balannec, G. Hotier, in: G. Ganetsos, P.E. Barker (Eds.), Preparative and Production Scale Chromatography, Marcel Dekker, New York, 1993, Ch. 14, p. 301.

[36] K. Gottschall, M. Kay, J. Reusch, Poster presentation at PREP'94, Baden-Baden, 1994.

[37] E.R. Francotte, P. Richert, J. Chromatogr. A 769 (1997) 101.

[38] M. Schulte, R. Ditz, R.M. Devant, J.N. Kinkel, F. Charton, J. Chromatogr. A 769 (1997) 93.

[39] L.S. Pais, J.M. Loureiro, A.E. Rodrigues, AIChE J. 44 (1998) 561.

[40] R.-M. Nicoud, LC·GC Int. 6 (1993) 636.

[41] A.M. Rizzi, J. Chromatogr. 478 (1989) 71.

[42] B.-G. Lim, C.-B. Ching, R. Tan, Sep. Technol. 5 (1995) 213.

[43] R.-M. Nicoud, G. Fuchs, P. Adam, M. Bailly, E. Küsters, F.D. Antia, R. Reuille, E. Schmid, Chirality 5 (1993) 267.

[44] R.-M. Nicoud, M. Bailly, J.N. Kinkel, R. Devant, T. Hampe, E. Küsters, in: R.-M. Nicoud (Ed.), Simulated Moving Bed: Basics and Applications, Separex and ENSIC, INPL, Nancy, 1993, p. 65.

[45] A. Seidel-Morgenstern, G. Guiochon, Chem. Eng. Sci. 48 (1993) 2787. 
[46] A. Seidel-Morgenstern, G. Guiochon, J. Chromatogr. 631 (1993) 37.

[47] R.-M. Nicoud, A. Seidel-Morgenstern, in: R.-M. Nicoud (Ed.), Simulated Moving Bed: Basics and Applications, Separex and ENSIC, INPL, Nancy, 1993, p. 4.

[48] S. Jacobson, S. Golshan-Shirazi, G. Guiochon, AIChE J. 37 (1991) 836

[49] L.S. Pais, J.M. Loureiro, A.E. Rodrigues, Chem. Eng. Sci. 52 (1997) 245.

[50] D.M. Ruthven, C.B. Ching, Chem. Eng. Sci. 44 (1989) 1011.

[51] G. Storti, M. Masi, S. Carrà, M. Morbidelli, Chem. Eng. Sci. 44 (1989) 1329.

[52] G. Storti, M. Mazzotti, M. Morbidelli, S. Carrà, AIChE J. 471 (1993) 39.

[53] M. Mazzotti, G. Storti, M. Morbidelli, AIChE J. 40 (1994) 1825.

[54] G. Storti, R. Baciocchi, M. Mazzotti, M. Morbidelli, Ind. Eng. Chem. Res. 34 (1995) 288.

[55] M. Mazzotti, G. Storti, M. Morbidelli, AIChE J. 42 (1996) 2784.

[56] M. Mazzotti, G. Storti, M. Morbidelli, AIChE J. 43 (1997) 64.

[57] A. Chiang, AIChE J. 44 (1998) 332.

[58] C.B. Ching, C. Ho, K. Hidajat, D.M. Ruthven, Chem. Eng. Sci. 42 (1987) 2547.

[59] C.B. Ching, C. Ho, D.M. Ruthven, Chem. Eng. Sci. 43 (1988) 703 .

[60] K. Hashimoto, S. Adachi, H. Noujima, H. Maruyama, J. Chem. Eng. Japan 16 (1983) 400.

[61] C.B. Ching, D.M. Ruthven, Chem. Eng. Sci. 40 (1985) 877.

[62] M.M. Hassan, A.S. Rahman, K.F. Loughlin, Sep. Technol. 4 (1994) 15.

[63] A.S. Rahman, M.M. Hassan, K.F. Loughlin, Sep. Technol. 4 (1994) 27.
[64] H. Schmidt-Traub, J. Strube, Comput. Chem. Eng. 20 (1996) S641.

[65] J. Strube, U. Altenhoner, M. Meurer, H. Schmidt-Traub, M. Schulte, J. Chromatogr. A 769 (1997) 81.

[66] L.S. Pais, J.M. Loureiro, A.E. Rodrigues, J. Chromatogr. A 769 (1997) 25.

[67] G. Zhong, G. Guiochon, Chem. Eng. Sci. 51 (1996) 4307.

[68] T. Yun, G. Zhong, G. Guiochon, AIChE J. 43 (1997) 935.

[69] K. Hidajat, C.B. Ching, D.M. Ruthven, Chem. Eng. J. 33 (1986) B55.

[70] K. Hidajat, C.B. Ching, D.M. Ruthven, Chem. Eng. Sci. 41 (1986) 2953

[71] G. Storti, M. Masi, R. Paludetto, M. Morbidelli, S. Carrà, Comput. Chem. Eng. 12 (1988) 475.

[72] K.H. Chu, M.A. Hashim, Chem. Eng. J. 56 (1995) 59.

[73] G. Hotier, AIChE J. 42 (1996) 154.

[74] M.M. Hassan, A.S. Rahman, K.F. Loughlin, Sep. Technol. 5 (1995) 77.

[75] B.G. Lim, C.B. Ching, Sep. Technol. 6 (1996) 29.

[76] G. Zhong, G. Guiochon, Chem. Eng. Sci. 52 (1997) 3117.

[77] G. Zhong, G. Guiochon, Chem. Eng. Sci. 52 (1997) 4403.

[78] G. Bader, U. Ascher, SIAM J. Sci. Stat. Comput. 8 (1987) 483.

[79] M. Mazzotti, M. Pedeferri, M. Morbidelli, in: Proceedings of the Chiral Europe'96 Symposium, Stockport, 1996, p. 103.

[80] M. Mazzotti, G. Storti, M. Morbidelli, J. Chromatogr. A 769 (1997) 3.

[81] Reference Manual, IMSL International Mathematical and Statistical Libraries, Inc., TX, 1982.

[82] E. Kusters, G. Gerber, F.D. Antia, Chromatographia 40 (1995) 387. 